\title{
The evaluation of water quality and survey of benthic diversity in the
}

\section{Baiyangdian Lake (China)}

Hong-wei WANG ${ }^{1,2, \text { a }}$, Fang $\mathrm{CAl}^{3, \mathrm{~b}}$, Chun-long $\mathrm{ZHAO}^{4, \mathrm{c}^{*}}$, Chao-chen $\mathrm{YANG}^{4, \mathrm{~d}}$, Yu FAN ${ }^{1, e}$, Yan DING ${ }^{1, f}$, Jia-yu ZHANG ${ }^{1, g}$, Jia-hua LIU ${ }^{1, h}$

1. The Key Laboratory of Zoological Systematics and Application, College of Life Science, Hebei University, Baoding, P.R. China

2. South China Institute of Environmental Sciences, MEP, Guangzhou, P.R .China

3. Plant protection station of Beijing City, Beijing , P.R .China

4. Marine Living Resources and Environment Key Laboratory of Hebei Province,Qinhuangdao , P.R .China

awanghw6688@gmail.com, b85900389@qq.com, 'bio2008@126.com ( Communication author ), d2891285682@qq.com , eok200090@hotmail.com , ' whw66@hbu.edu.cn g906472733@qq.com, hhwoods@126.com

Keywords: Baiyangdian Lake, benthic macroinvertebrates, diversity index, evaluate Abstract: The investigation of benthic macroinvertebrates of Baiyangdian Lake was done in 2014. It contains the composition and diversity of benthic macroinvertebrates. Making an analysis of the survey result discovers that the diversity index of Yuanyang Island was the lowest as the sewage river entrance. No. 2 sampling point, which was the heavy polluted water, and the others were approximative, all being in the range of $1 \sim 2$, which were the moderately polluted water. Therefore, we can say that Baiyangdian Lake was moderately polluted water. Richness, Shannon Wiener diversity index, evenness index of the three annual change trend was consistent, to analyze the correlation between the index of richness and Shannon Wiener diversity, the results shows that the correlation coefficient is 0.929 , indicated correlation.

The main groups of benthic macroinvertebrates freshwater lake in Baiyangdian Lake were including the mollusca, annelid and aquatic insects. Due to the sensitive of benthic macroinvertebrates to the change of environment, when the water was polluted, the benthic macroinvertebrates community structure and diversity will change, accordingly, the types and characteristics of community as an environmental evaluation index has been widely used in the monitoring of water quality in lakes.

\section{Materials and Methods}

Sampling environment :Nanliu Zhuang(Sewage river entrance), Yuanyang Island(sewage river 
water entrance area), Shaoche Dian(Hydrostatic storage area),Wangjia Zhai(The village of livestock and poultry breeding area),Zaoling Zhuang(Hydrostatic storage area), Guang Dian(Half a fish culture zone), Quan Tou(Half a fish culture zone), Caipu Tai(Natural zone), Duan Cun(Fish culture zone).

The benthic macroinvertebrates were collected in Baiyangdian Lake in 2014. There were 9 sampling points (Fig.1). Sampling tool was specific circumstances in accordance with the sampling point selection. 1/16 Peter's dredge, handline, spades, sampled 3 times in each sampling point, sediment with 60 mesh sieve filtration, screening out the sample into the wide mouth bottle fixed by formaldehyde, back to the laboratory to complete the identification and counting weighing work. Evaluation index of diversity and integrity were inspected after the completion of the work. Correlation analysis of the experimental data were using SPSS 13.0 software processing.

Calculation formula:

The richness index is Margalef's index, Calculation formula,

$$
d=(\mathrm{S}-1) / \log _{2} \mathrm{~N}
$$

$\mathrm{d}=$ Species richness $\quad \mathrm{S}=$ species' number $\quad \mathrm{N}=$ the total number of individuals

The Shannon Wiener index calculation method follows,

$$
H^{\prime}=-\Sigma\left(\mathrm{p}_{1}\right)\left(\log _{2} \mathrm{p}_{1}\right) \cdot \cdot
$$

$\mathrm{P} i=$ the " $i$ " proportion of Species richness in total, such as, $\mathrm{N}=$ Species richness, $\mathrm{n} i=$ the Species richness of " $i$ ", and $\mathrm{P} i=\mathrm{n} i / \mathrm{N}$

Pielou' sevenness index, by estimating the maximum Shannon theory of Wiener index H'max, and then to the actual measured $\mathrm{H}^{\prime}$ ratios of Max to $\mathrm{H}^{\prime}$,

the calculation formula is $J^{\prime}=H^{\prime} / H^{\prime} \max$

$\mathrm{J}^{\prime}=$ Pielou' sevenness index $\quad \mathrm{H}^{\prime}=$ Species richness index $\quad \mathrm{H}^{\prime} \max =$ the number of species

There is the H' max when all the species richness are the same, H' reaching the highest.

So, $H^{\prime} \max =\log _{2} S \quad \mathrm{~J}^{\prime}=\mathrm{H}^{\prime} / \log _{2} \mathrm{~S} \quad \mathrm{~J}^{\prime}=\quad$ Pielou' sevenness index

$H^{\prime}=$ Species richness index,$\quad S=$ species' number

\section{Results}

Analysis of benthic macroinvertebrates diversity index and water quality in Baiyangdian Lake. Calculate the diversity index of every species, and then the sum index of every species is the diversity index of every point. The diversity indexes of benthic macroinvertebrates of every sampling point were shown as follow. 


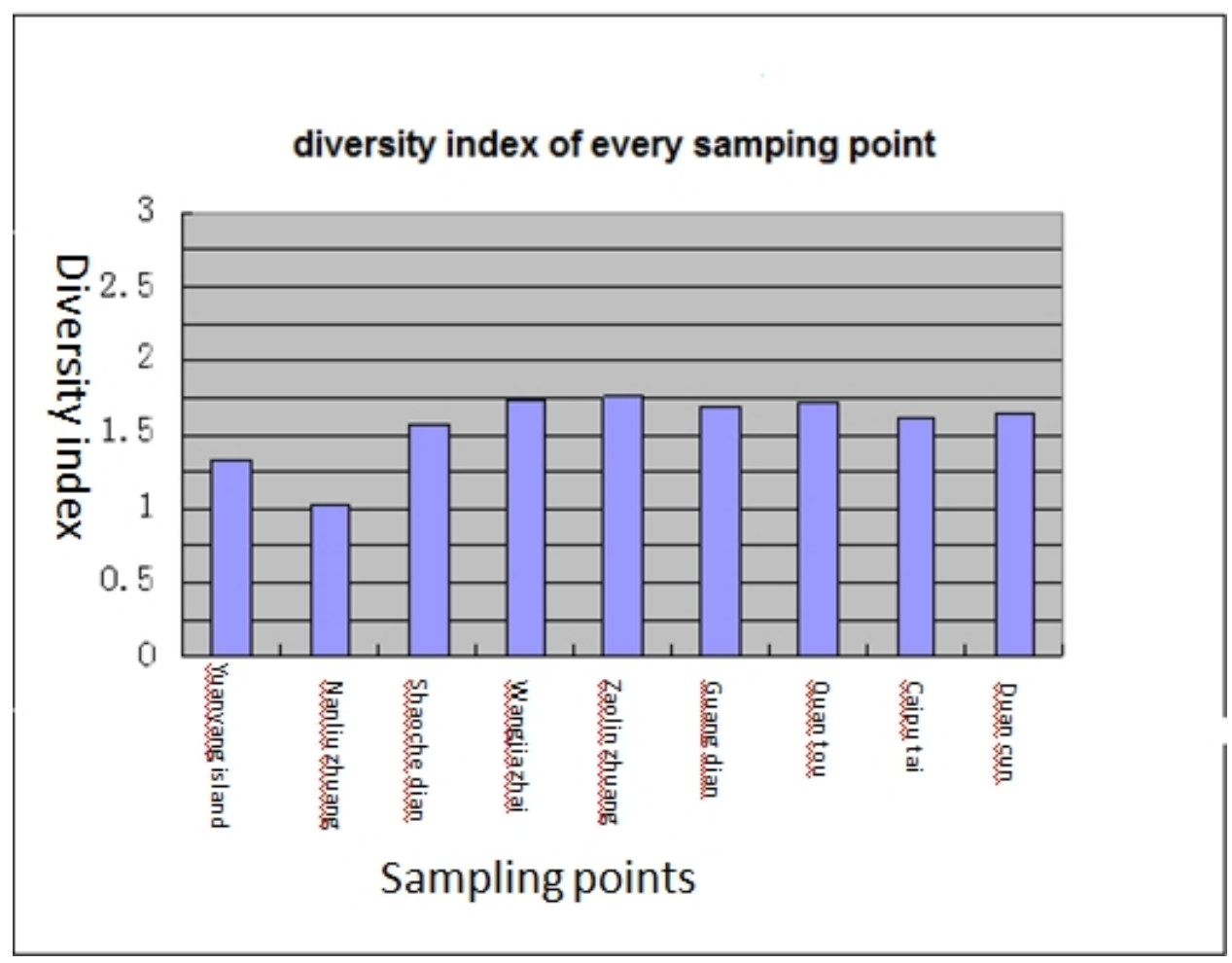

Fig.2 The diversity index of every sampling points in Baiyangdian Lake

Fig. 2 shows, as the sewage river entrance No. 2 sampling point Yuanyang Island being lowest diversity index, is heavy polluted water, and the remaining few sampling points close to the diversity index in the range of $1 \sim 2$, is moderate pollution, so we can say that the water of Baiyangdian is moderate pollution. Analysis of the main reason lies in the agricultural and industrial wastewater and domestic sewage discharge.

The index of diversity of benthic macroinvertebrates Shannon-Wiener is often used to evaluate the water by human impact.

Reference resources "Aquatic biological monitoring manual"

The degree of influence can be divided into 4 types , $\mathrm{H}^{\prime}=0$, is seriously affected by human; $0<\mathrm{H}^{\prime}<1$, is the severe impact; $\mathrm{H}^{\star}=1 \sim 3$, is middle impact; $\mathrm{H}^{\prime}>3$, is no impact.

\section{Discussion}

The survey found that 9 sampling points of especially the sewage river entrance (Nan Liu Zhuang, Yuanyang Island) with serious pollution and Chironomidae, Oligochaeta density and biomass is relatively large, and often one or a few species are dominant, the benthic macroinvertebrates community structure tended to be simple, the diversity the index is relatively small. Analysis of the main reason lies in the agricultural and industrial wastewater and domestic sewage discharge. The diversity of benthic macroinvertebrates is reduced due to eutrophication and aquatic plant communities caused by water pollution.

Recently, approved by the provincial government, the Baiyangdian Lake provincial natural protection area was formally established. Baiyangdian Lake is the largest freshwater wetlands in North China region, rich in biodiversity, habitat for hundreds of species of birds. After the establishment of nature reserves, we can do something further to the regional ecological environment evolution, prediction and research of continuous system, which is conducive to the reduction of Baiyangdian and the surrounding areas of ecological damage caused by the irrational 
development activities, and to the protection of biodiversity and wildlife gene bank protection and wetland ecological system.

\section{Acknowledgements}

We wish to thank Prof. Zhiping MEI, Dr. Zhenyu ZHANG and Dr. Yifeng DU editing this manuscript. We are grateful for the constructive comments of the reviewers. This research was supported by NSFC U1133005 ; The natural science foundation of Hebei Province

( D2013201105 ) ; The Education Department of Hebei province key project ( 2013-77 ) ; Start project for returned overseas researchers of Hebei Province (2013) ; The Project-sponsored by SRF for ROCS , SEM(2014); Hebei Characteristics of Seafood Innovation Team of Modern Agro-industry Technology Research System ; Projects of coastal habitat restoration in Qinhuangdao (Provincial Science and Technology Department, No. 15273303D) ;Hebei Provincial Key Laboratory of operating subsidy (item number: 14967611D) ; Funded by Hebei Province project for cultivating national key disciplines in biology ; Funded by Heibei Province construction project in Strong and characteristic disciplines of biology.

\section{Reference :}

[1] Maurizio Pinna, Gabriele Marini, Giorgio Mancinelli, Alberto Basset.Influence of sampling effort on ecological descriptors and indicators in perturbed and unperturbed conditions: A study case usingbenthic macroinvertebrates in Mediterranean transitional waters.Ecological Indicators, 2014, 37, Part A, 27-39.

[2] Pilar Molina, F. Patricio Ojeda, Marcela Aldana, V.M. Pulgar, M. Roberto García-Huidobro, José Pulgar.Spatial and temporal variability in subtidal macroinvertebrates diversity patterns in a management and exploitation area forbenthic resources (MEABRs). Ocean \& Coastal Management, 2014, 93, 121-128.

[3] Henry Joutsijoki, Kristian Meissner, Moncef Gabbouj, Serkan Kiranyaz, Jenni Raitoharju, Johanna Ärje, Salme Kärkkäinen, Ville Tirronen, Tuomas Turpeinen, Martti Juhola. Evaluating the performance of artificial neural networks for the classification of freshwater benthic macroinvertebrates. Ecological Informatics, 2014, 20, 1-12. 